\title{
The relationship of the characteristics of fashion brand SNS, relationship quality and purchase intention \\ - Focusing on Facebook -
}

Yoojung Lee and Nam Hae $\mathrm{Cho}^{\dagger}$

Dept. of Clothing \& Textiles, Ewha Womans University, Korea

\author{
패션 브랜드 SNS의 특성, 관계의 질 및 구매의도의 관계 \\ - 페이스북(Facebook)을 중심으로 - \\ 이 유 정·조 남 혜 ${ }^{\dagger}$ \\ 이화여자대학교 의류학과
}

\begin{abstract}
This study investigated the relationship of fashion brand SNS characteristics, relationship quality (satisfaction, trust, and commitment) and purchase intention. The study focused on Facebook and also examined the difference between fashion involvement groups. This study targeted consumers who have used fashion brand Facebook and are aged between 20s and 30s. Data collection was conducted through surveys, and a total 205 questionnaires were collected for the final statistical analysis. The major findings of the study were as follows. First, three characteristics of fashion brand SNS, which were entertainment, interactivity, and providing information, influenced positively on SNS users' satisfaction. Entertainment had the greatest influence on satisfaction, and providing information and interactivity followed. Second, satisfaction for fashion brand SNS influenced positively on trust and commitment. Also, trust to fashion brand SNS demonstrated a positive influence on commitment. Third, trust and commitment on fashion brand SNS both influenced positively on purchase intention. Fourth, the fashion involvement groups showed differences in fashion brand SNS characteristics, relationship quality, and purchase intention. The high involvement group showed much higher results in all aspects then did the low involvement group. Based on the above results, this study has a significant value which suggests directions for future research. Also, this paper is expected to provide managerial implications to fashion companies which need to develop SNS marketing strategies.
\end{abstract}

Keywords: SNS characteristics(SNS 특성), relationship quality(관계의 질), purchase intention(구매의도), fashion involvement (패션관여도)

Received 2 September 2014, revised 6 October 2014, accepted 8 October 2014.

${ }^{\dagger}$ Corresponding author (clonh@naver.com)

This is an Open Access article distributed under the terms of the Creative Commons Attribution Non-Commercial License (http://creativecommons.org/licenses/by-nc/3.0) which permits unrestricted non-commercial use, distribution, and reproduction in any medium, provided the original work is properly cited. 


\section{Introduction}

최근 많은 기업들이 페이스북(Facebook), 트위터 (Twitter) 등으로 대표되는 SNS(Social Network Service) 를 소비자와의 소통 채널 및 마케팅 도구로 활용하 는 추세이다. SNS란 인터넷상에서 타인과의 인맥 을 형성-강화하여 광범위한 인적 네트워크를 구 성할 수 있도록 해주는 서비스로서, 사람들 간의 관계를 기반으로 정보나 콘텐츠를 생산, 교류, 소비 할 수 있도록 도와준다(KISA, 2009). 오늘날 무선 인터넷의 발달과 스마트폰의 대중화에 힘입어 SNS 이용자는 급증하고 있으며, SNS는 일상적인 커뮤 니케이션 채널로 정착되고 있다.

이에 따라 패션 기업들은 최근 $\mathrm{SNS}$ 를 활용하여 다양한 비즈니스 모델을 구축하고 있는데, 페이스 북은 패션 마케팅 도구로서 높은 매력도를 지닌다. 페이스북은 텍스트와 더불어 사진 및 동영상 등 다 양한 콘텐츠의 직접적 공유가 가능하기에, 여러 SNS 중 패션 브랜드가 효과적으로 제품 및 서비스 정보 를 소비자에게 제공할 수 있다. 패션 제품의 경우, 소비자의 구매의도를 제고시키기 위해서는 시각적 자극이 매우 중요하므로 시각적 콘텐츠를 활용한 홍보가 요구된다. 따라서 페이스북은 패션 브랜드 의 SNS 마케팅 측면에서 활용도가 높다고 할 수 있다.

이처럼 오늘날 패션 브랜드들이 SNS 마케팅을 실 시하는 이유는 소비자와 기업의 관계의 질(relationship quality)을 제고시키기 위함이다. 특정 기업과 장기적 관계를 지속하고자 하는 소비자의 강한 의 지를 뜻하는 관계의 질은 소비자의 구매의사결정에 있어 매우 중요한 변수로 파악된다(Crosby, Kenneth \& Cowles, 1990; Morgan \& Hunt, 1994; Wulf, Schroder \& Iacobucci, 2001). 그동안 패션마케팅 분야에서는 관계의 질(만족, 신뢰, 몰입)에 대한 연구가 지속되 어 왔으나, 관계의 질 각 변수 간의 관계를 설명한 연구는 미흡하였다. 따라서 패션 브랜드 SNS의 이 용에 따른 관계의 질에 대한 연구는 학문적, 실무 적 측면에서 중요한 가치를 지닐 것으로 판단된다. 이에 본 연구에서는 패션 브랜드의 SNS 마케팅 활동이 관계의 질 형성에 미치는 영향에 대해 파악 하고, 이에 따른 구매의도에 관하여 알아보고자 하
였다. 본 연구는 여러 SNS 중 페이스북을 중심으로 패션 브랜드의 SNS를 연구하였으며, 조절변수로서 패션관여도에 따른 집단 간 $\mathrm{SNS}$ 특성의 지각, 관계 의 질, 구매의도의 차이에 대해서도 살펴보았다.

\section{Background}

\section{Characteristics of SNS}

SNS란 '소셜 네트워크 서비스(Social Network Service)'의 줄임말로, 인터넷을 기반으로 인맥을 형성 하고, 개인적 관심사 및 전문 정보나 지식을 공유 하며, 1 인 미디어, 1 인 커뮤니티로서 자기표현 및 홍보(PR) 등 다양한 활동을 할 수 있는 서비스를 의미한다(KISA, 2012).

최근 많은 패션 기업들이 SNS를 마케팅 도구 및 소비자와의 커뮤니케이션 채널로서 활용하고 있는 데, Marketing Executives Networking Group의 연구 (Ryu 재인용, 2009)에 따르면 이는 기업이 SNS 마 케팅을 통해 ‘고객 참여'라는 가장 큰 이익을 얻을 수 있기 때문이다. SNS를 통해 기업은 소비자에게 메시지를 쉽고 빠르게 전달할 수 있으며, 고객의 위치에 상관없이 메시지를 전달할 수 있고, 관심과 친분을 바탕으로 고객에게 신뢰를 줄 수 있으며, 새 로운 고객 또는 팬(fan)을 확보하기에 용이하다(Ryu, 2009). 이처럼 SNS는 고객과의 커뮤니케이션을 최 대치로 이끌어낼 수 있고, 그 파급 효과 또한 매우 크기에 현재까지 제시되어온 수많은 마케팅 수단 중 가장 매력적인 마케팅 채널로 평가된다(Lee and Lee, 2012).

여러 선행연구들을 통해 SNS의 특성은 유희성, 상호작용성, 그리고 정보제공성을 중심으로 논의되 었는데, 구체적인 내용은 다음과 같다.

\section{1) Entertainment}

유희성(entertainment)이란 예측되는 성과의 중요 성과 상관없이, 사용자가 정보시스템 사용 행위에 대해 스스로 즐겁다고 지각하는 정도를 의미한다 (Davis, Bagozzi \& Warshaw, 1992). 즉, SNS의 유희 성이란 $\mathrm{SNS}$ 를 사용하면서 재미나 흥미를 느끼게 하는 것에 대하여 스스로 지각하는 정도를 일컫는 다고 할 수 있다(Kang, 2012; Yang, 2012). 
Kim and $\mathrm{Oh}(2004)$ 는 브랜드의 온라인 커뮤니티 에서 기업이 구성원들에게 재미있는 이벤트나 게 임을 제공함으로써 구성원들이 즐겁고 흥미진진한 감정을 갖게 되면, 구성원들이 보다 높은 소속감과 유대감을 가지게 되고, 결과적으로 구성원의 수가 증대된다고 하였다. 이는 가상 커뮤니티가 뚜렷한 흥미를 주축으로 이루어진다고 주장한 Bagozzi and $\mathrm{Utpal}(2002)$ 의 연구와도 같은 맥락으로 볼 수 있다. 따라서 SNS에서도 이처럼 기업이 소비자에게 재미 요소를 적극적으로 제공한다면, 이벤트에 참여하는 팬과 기업 간의 결속력 및 충성도를 제고시키는 커 뮤니티 효과를 기대할 수 있을 것이다(Kim, 2011).

한편, SNS의 재미 요소는 SNS 이용자의 만족도 에 긍정적 영향을 미치는 것으로 선행연구들을 통 해 확인되었는데, Lee(2011), Lee and Lee(2012)의 연구에서 기업 $\mathrm{SNS}$ 의 오락성은 $\mathrm{SNS}$ 에 대한 고객 만족에 유의한 영향을 미치는 것으로 나타났다. 또 한, $\operatorname{Kim}(2012)$ 은 $\mathrm{SNS}$ 의 유희성이 이용자의 만족도 에 긍정적 영향을 준다고 하였다.

이에 본 연구에서는 패션 브랜드 $\mathrm{SNS}$ 의 유희성 이 관계의 질 형성 요인 중 하나인 만족에 유의한 영향을 미치는지에 대하여 연구하고자 하였다. 선 행연구를 바탕으로 도출된 본 연구의 가설은 다음 과 같다.

가설 1. 패션 브랜드 SNS의 유희성은 만족에 긍 정적 영향을 미칠 것이다.

\section{2) Interactivity}

상호작용성(interactivity)이란 이용자 개개인의 특 성을 파악하고, 그 개인의 반응을 수집· 기억하여, 이 후의 커뮤니케이션 과정에서 이전에 수집한 정보를 활용해 개인의 특성에 알맞도록 재반응하는 일련의 메시지 교환을 의미한다(Deighton, 1996). Blattberg and Deighton(1991)은 시공간의 제약 없이 개인 또 는 집단이 서로 직접적으로 커뮤니케이션하는 작 용을 가리켜 상호작용성이라 정의하였다. Anderson (1996)의 연구에서는 이러한 상호작용적 커뮤니케 이션이 당사자의 만족뿐만 아니라, 상대방에 대한 친밀감을 높여 커뮤니케이션 상대방에 대한 몰입 으로까지 이어지는 것으로 나타났다.
상호작용성은 기존의 웹사이트와 구별되는 SNS 의 핵심적 특성이라 할 수 있다(Kang, 2012). SNS 이용자들 간의 상호작용은 서비스의 부수적 산물 이 아닌 핵심요소이며, 이용자들 간의 상호작용을 통해 지속적으로 콘텐츠가 생산되고 확대될 수 있 기 때문이다(Ryu, 2009). 즉, 상호작용성은 고객의 지속적인 $\mathrm{SNS}$ 이용을 이끌어내고, 이를 통해 $\mathrm{SNS}$ 의 가치를 극대화시키는 SNS의 핵심 요인인 것이 다(Lee, 2011).

Lee and Lee(2012)는 SNS의 상호작용성이 만족 도, 신뢰도, 몰입도를 거쳐 고객 충성도 제고에까지 유의한 영향을 미치는 것을 확인하였다. 이에 본 연구에서는 선행연구를 토대로 패션 브랜드 SNS의 상호작용성이 관계의 질 형성 요인 중 하나인 만족 에 유의한 영향을 미치는지에 대하여 연구하고자 하였다. 선행연구를 바탕으로 도출된 본 연구의 가 설은 다음과 같다.

가설 2. 패션 브랜드 $\mathrm{SNS}$ 의 상호작용성은 만족 에 긍정적 영향을 미칠 것이다.

\section{3) Providing information}

정보제공성(providing information)이란 기업이 소 비자에게 제공하는 서비스 관련 정보가 축적되고, 축적된 정보를 토대로 소비자가 서비스에 대해 판단 을 내리게 되는 과정을 의미한다(Smith \& Swinyard, 1983). Hong(2012)은 SNS를 통해 축적된 정보의 질과 양에 따라 기업의 서비스에 대한 소비자의 판 단이 달라지며, 이는 재구매 행동이나 타인에게 추 천하는 행동에까지 영향을 미친다고 하였다.

오늘날 기업은 $\mathrm{SNS}$ 를 통해 자사의 신제품 정보 나 새로운 광고, 기업 관련 뉴스 및 이벤트 등에 관 한 다양한 정보를 실시간으로 소비자에게 제공한 다(Yang, 2012). 소비자는 SNS를 통해 기업 관련 정 보를 쉽고 빠르게 제공받을 수 있으며, 이러한 공 개적 정보 교환은 정보의 전달을 더욱 촉진시키고 정보의 진실성을 제고시키는 효과를 지닌다(Oh, 2010).

$\mathrm{Lee}(2011)$ 의 연구에서 기업 SNS의 정보성은 고 객 만족을 매개변수로 하여 방문의도 및 충성도에 유의한 영향을 미치는 것으로 나타났다. 또한, $\mathrm{Kim}$ (2012)의 연구에서는 SNS의 정보성이 SNS 이용자 
만족도에 긍정적 영향을 미치며, SNS 이용자 만족 도는 곧 SNS 이용의도에 긍정적 영향을 미치는 것 으로 확인되었다.

이에 본 연구에서는 패션 브랜드 SNS의 정보제 공성이 관계의 질 형성 요인 중 하나인 만족에 유 의한 영향을 미치는지에 대하여 연구하고자 하였 다. 선행연구를 바탕으로 도출된 본 연구의 가설은 다음과 같다.

가설 3. 패션 브랜드 SNS의 정보제공성은 만족 에 긍정적 영향을 미칠 것이다.

\section{Relationship quality}

관계의 질(relationship quality)이란 소비자가 기 업과 거래를 지속하고자 하는 의지에 강한 영향을 미치는 개념으로, 관계 결정 요인과 관계의 성과의 매개변수로서 제시되는데, 여기서 관계의 성과란 구매의도나 재구매의도, 또는 브랜드 충성도를 뜻 한다(Crosby et al., 1990; Morgan \& Hunt, 1994; Wulf, Schroder \& Iacobucci, 2001).

관계의 질은 서로 관련 있는 각각의 독특한 차원 으로 이루어진 고차원적 구조물로서, 그동안 학자 에 따라 관계의 질을 구성하는 요인이 명확히 일치 하지는 않았으나, 여러 선행연구들을 통해 만족, 신 뢰, 몰입이 관계의 질을 가장 잘 설명하는 요인으 로 밝혀져 왔다(Wulf et al., 2001). 이는 SNS와 관 련된 연구에서도 밝혀진 바 있는데, Lee and Lee (2012)는 SNS에 대한 만족도가 신뢰도 및 몰입도 에 영향을 미침으로써 관계의 질이 형성된다고 하 였다. 이에 본 연구에서는 관계의 질을 구성하는 요인으로 만족, 신뢰, 몰입을 규정하였고, 패션 브 랜드의 SNS 마케팅에 따른 소비자와 패션 브랜드 $\mathrm{SNS}$ 간의 관계의 질에 대해 살펴보았다.

\section{1) Satisfaction}

만족(satisfaction)이란 소비자가 자신의 욕구가 어 느 정도 채워졌는지에 대해 판단하는 반응을 의미 한다(Oliver, 1993). Oliver(1980)는 만족과 관련하여 기대-불일치 패러다임을 제시하였으며, 특정 거래 의 지각된 성과를 기대와 비교 평가한 판단을 만족 이라 정의하였다. 이처럼 만족은 소비자의 욕구 및
기대에 대한 평가와, 구매 후 소비자 행동 예측에 효과적이기에 오늘날 마케팅의 핵심 변수로 간주 되고 있다(Hwang \& Hwang, 2005; Lee, Lee, Park \& Park, 2007; Seo \& Lee, 2008).

기업의 서비스에 대한 고객의 만족은 해당 기업에 대한 신뢰 형성으로 이어진다(Fornell, 1992; Ganesan, 1994; Garbarino \& Johnson, 1999; Morgan \& Hunt, 1994). 이는 패션마케팅 분야의 여러 선행연구(Hwang \& Hwang, 2005; Ju \& Chung, 2007; Lee, Yu \& Park, 2009)들을 통해서도 확인되었다. 또한, 만족 은 몰입의 선행변수로도 작용하는데, Oliver(1997) 와 Smith(1998)는 판매자와의 상호작용에 만족한 고객이 판매자에 대한 몰입을 형성함을 확인하였 다. 이는 패션 점포에 대한 만족이 몰입으로 이어 지는 것으로 나타난 Hwang and Hwang(2005), Seo and Lee(2008)의 연구 결과를 뒷받침한다.

한편, $\mathrm{SNS}$ 상에서도 $\mathrm{SNS}$ 에 대한 만족도는 $\mathrm{SNS}$ 에 대한 신뢰도 및 몰입도에 유의한 영향을 미치는 것으로 나타났다(Lee \& Lee, 2012). 이에 본 연구에 서는 선행연구를 토대로 패션 브랜드 SNS에 대한 만족이 패션 브랜드 SNS에 대한 신뢰와 몰입 형성 에 유의한 영향을 미치는지에 대하여 연구하고자 하였다. 본 연구에서 선정된 연구 가설은 다음과 같다.

가설 4. 패션 브랜드 SNS에 대한 만족은 패션 브랜 드 SNS에 대한 신뢰에 긍정적 영향을 미칠 것이다.

가설 5. 패션 브랜드 SNS에 대한 만족은 패션 브랜 드 $\mathrm{SNS}$ 에 대한 몰입에 긍정적 영향을 미칠 것이다.

\section{2) Trust}

신뢰(trust)란 고객과 판매자와의 관계에서 지각 된 진실성과 호의성을 의미한다(Doney \& Cannon, 1997). Doney and Cannon의 연구(Hwang \& Hwang 재인용, 2005)에 따르면 진실성이란 판매자의 말 또는 서면상의 진술을 수 있는 기대치를 뜻하며, 호의성이란 판매자가 고객의 복리에 대해 갖고 있 는 진지한 관심과 공동의 이익을 찾고자 하는 정도 를 의미한다. Swan, Bower, and Richardson(1999)은 관계의 질을 결정하는 중요 요소로서 신뢰를 규정 하였으며, 관계에 대해 신뢰할수록 소비자는 그 관 
계를 가치 있는 것으로 간주하게 되고, 불확실성이 존재하는 새로운 거래 파트너를 찾기 보다는 그 관 계 속에 머무르고자 하는 경향을 나타낸다고 하였 다. 이처럼 신뢰는 기업이 소비자와 장기적이며, 우 호적인 관계를 맺기 위해 반드시 필요한 요소이며, 기업은 이를 통해 지속적인 성장과 존속을 도모할 수 있다(Moorman, Deshpande \& Zaltman, 1993; Morgan \& Hunt, 1994).

여러 선행연구(Dwyer, Schurr \& Oh, 1987; McDonald, 1981; Morgan \& Hunt, 1994; Schemwell, Cronin \& Bullard, 1994)들을 통해 신뢰는 몰입의 선행변수임 이 확인되었는데, 패션 분야에서도 매장 및 매장 직원에 대한 신뢰는 몰입에 유의한 영향을 미치는 것으로 밝혀졌다(Hwang \& Hwang, 2005; Ju \& Chung, 2007; Lee et al., 2009; Seo \& Lee, 2008). 이에 본 연구에서는 선행연구들을 토대로 패션 브랜드 SNS 에 대한 신뢰가 패션 브랜드 SNS에 대한 몰입 형 성에 유의한 영향을 미치는지에 대하여 연구하고 자 하였다. 본 연구의 가설은 다음과 같다.

가설 6. 패션 브랜드 SNS에 대한 신뢰는 패션 브랜 드 $\mathrm{SNS}$ 에 대한 몰입에 긍정적 영향을 미칠 것이다.

\section{3) Commitment}

몰입(commitment)이란 소비자가 기업과의 가치 있는 관계를 지속적으로 유지하고자 하는 욕구를 의미한다(Moorman et al., 1993). Morgan and Hunt (1994)는 몰입이란 고객과 기업의 관계에서 서로가 교환 관계를 지속시키고자 하는 노력이라고 정의 하였다. 몰입은 관계를 유지하기 위한 가장 높은 수준의 결속 정도로 인식되고 있으며, 기업은 몰입 을 통해 궁극적으로 고객과의 장기적인 관계를 형 성할 수 있다(Ju \& Chung, 2007; Seo \& Lee, 2008). 이로 인해 몰입은 오늘날 소비자와의 관계마케팅 을 추구하는 모든 기업에게 가장 중요한 요소이자, 신뢰와 함께 관계마케팅의 핵심변수로서 간주되고 있다(Morgan \& Hunt, 1994).

이에 본 연구에서는 기존의 연구들을 토대로 패 션 브랜드 SNS에 대한 만족과 신뢰가 패션 브랜드 $\mathrm{SNS}$ 에 대한 몰입으로까지 이어지는지에 대하여 연 구하고자 하였다.

\section{Purchase intention}

구매의도(purchase intention)란 특정 제품을 구매하 고자 하는 소비자의 의향 정도를 의미하며, 소비자의 예기된 혹은 계획된 미래 행동이 신념과 태도로 행동 화될 수 있는 가능성을 뜻한다(Engel \& Blackwell, 1982). 구매의도는 오늘날 구매의사결정 변수 중 가장 중요한 변수로 인식되고 있다(Engel, Blackwell \& Minard, 1990).

Moorman et al.(1993)과 Morgan and Hunt(1994) 는 기업에 대한 소비자의 신뢰를 통해 기업이 지속 적인 성장과 존속을 도모할 수 있다고 보았는데, 이는 소비자의 신뢰가 기업의 이익 창출, 즉 소비 자의 구매의사결정에 중요한 영향을 미친다는 점 을 시사한다. 이를 통해 신뢰가 구매의도에 유의한 영향을 미칠 수 있다는 가능성을 도출해낼 수 있다.

한편, $\operatorname{Raj}(1982)$ 는 몰입이 만족으로부터 영향을 받아 형성되고, 이는 궁극적으로 구매행동으로까지 이어진다고 하였다. 또한, Garbarino and Johnson (1999)은 몰입이 형성된 관계에서 소비자는 기업의 향후 안녕을 기원하게 되고, 이를 위한 행동을 수 반한다고 보았는데, 여기서 기업의 향후 안녕을 위 한 행동이란 소비자의 구매의사결정을 포함하는 개념이라 할 수 있다.

이에 본 연구에서는 기존의 연구들을 토대로 패 션 브랜드 SNS에 대한 신뢰와 몰입이 해당 브랜드 제품의 구매의도에 유의한 영향을 미치는지에 대 해 연구하고자 하였다. 본 연구에서 선정된 연구 가설은 다음과 같다.

가설 7. 패션 브랜드 $\mathrm{SNS}$ 에 대한 신뢰는 구매의 도에 긍정적 영향을 미칠 것이다.

가설 8. 패션 브랜드 $\mathrm{SNS}$ 에 대한 몰입은 구매의 도에 긍정적 영향을 미칠 것이다.

\section{Fashion involvement}

Antil의 연구(Yang 재인용, 2008)에 따르면 관여 (involvement)란 특정 상황에서 자극에 의해 촉발되 어 지각된 개인적 중요성 혹은 흥미의 수준을 의미 한다. Yang(2008)은 관여도가 높아질수록 소비자는 구매 관련 정보에 주의를 기울이게 되며, 관련 정 보를 이해하고 정교화 시키고자 더욱 동기화된다 
고 보았다.

패션마케팅 분야에서는 패션관여도에 대한 연구가 주로 이루어지고 있는데, 패션관여도(fashion involvement)란 의복을 구매할 때 특정 상황에서 자극에 의해 촉발되는 특정 대상에 대한 개인의 관련성 지 각 정도 또는 중요성 지각 정도를 뜻한다(Ahn, Hwang \& Jung, 2010; Kang \& Park, 2003).

패션관여도는 오늘날 다차원적 개념으로 이해될 수 있으며(Ha \& Kim, 2008; Kim \& Hwang, 2013; Song \& Hwang, 2007), 여러 선행연구들을 통해 패 션관여도에 따라 집단 간 패션 정보원 활용 유형, 패션 성향, 구매의도, 구전의도 등 다양한 측면에서 유의한 차이가 있는 것으로 확인되었다(Kim, 2011). 이에 본 연구에서는 패션관여도에 따른 집단 간 차 이가 존재할 것이라 보았고, 다음과 같은 연구가설 을 선정하였다.

가설 9. 패션관여도가 높을수록 패션 브랜드 SNS 특성의 지각, 관계의 질, 구매의도가 높을 것이다.

\section{Methods}

\section{Research model}

본 연구의 가설을 토대로 도출된 연구모형은 Fig. 1 과 같다.

\section{Measurement instrument}

본 연구는 선행연구를 통해 신뢰성과 타당성이 입증된 측정도구를 채택하여 본 연구의 목적에 부 합하도록 패션 브랜드 SNS 관련 문항으로 수정, 보 완하였다. 각 항목들은 리커트 5점 척도(1=전혀 그 렇지 않다, $5=$ 매우 그렇다)로 측정하였다. $\mathrm{SNS}$ 특 성은 유희성(Ahn, 2012; Lee, 2011; Park, 2013), 상 호작용성(Hong, 2012; Oh, 2012), 정보제공성(Ahn, 2012; Hong, 2012; Jeong, 2013)의 관련 선행연구들 을 참고하여 총 15 개 문항으로 구성하였다. 관계의 질은 만족(Ahn, 2012; Lee, 2003; Lee \& Lee, 2012; Park, 2013), 신뢰(Hong, 2012; Kim, 2011; Lee, 2012; Lee \& Lee, 2012), 몰입(Hong, 2012; Kim, 2011; Lee \& Lee, 2012)의 관련 선행연구들을 참고하여 총 13 개 문항으로 구성하였다. 구매의도는 Lee(2012), $\operatorname{Park}(2012)$ 의 연구에서 사용된 측정문항을 수정, 보 완하여 총 2 개의 문항으로 구성하였으며, 패션관여 도는 $\mathrm{Ha}$ and $\mathrm{Kim}(2008), \mathrm{Kim}(2011), \mathrm{Kim}$ and Hwang (2013), Song and Hwang(2007)의 연구에서 사용된 측정문항을 수정, 보완하여 총 9 개의 문항으로 구 성하였다. 본 연구의 설문지에는 이외에도 성별, 거 주지, 연령, 직업, 학력, 월평균 의복구매비용 등의 인구통계학적 특성과, 페이스북 및 패션 브랜드 페 이스북 페이지 사용 현황을 측정하는 문항이 포함 되었다.

\section{Data collection}

본 연구에서는 패션 브랜드의 페이스북 페이지

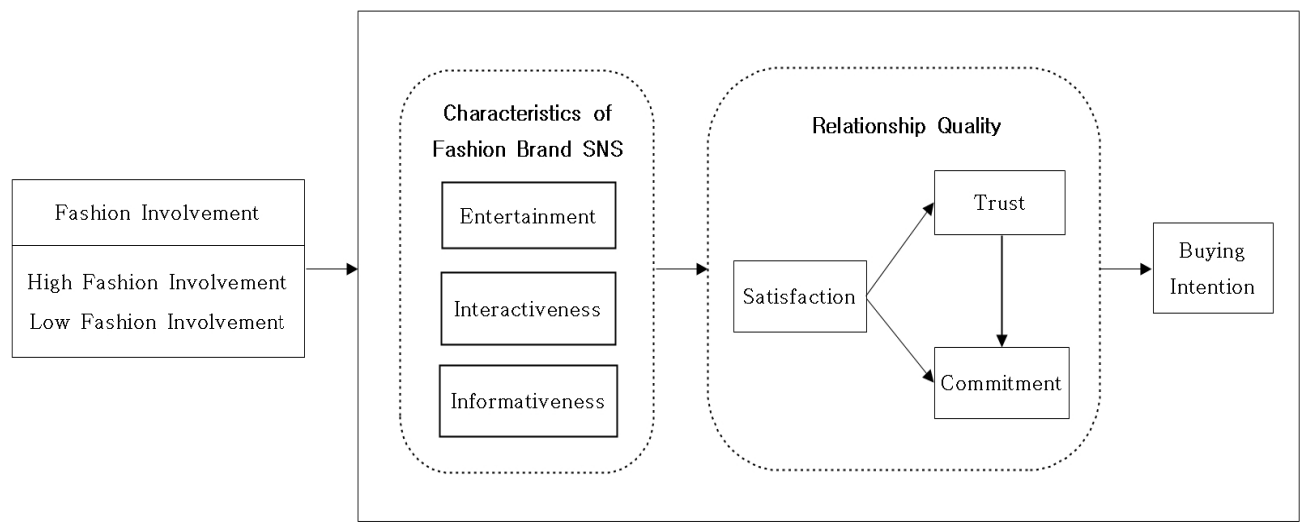

$\langle$ Fig. 1〉 Research model 
를 구독한 경험이 있고, 서울 또는 경기 지역에 거 주하는 20 30대 남녀 소비자들을 연구대상으로 선 정하였다. 자료 수집은 2013년 4월 28일부터 5월 9 일까지 설문지법을 통해 이루어졌으며, 220 부의 설 문지를 배포, 회수하여 응답내용이 불성실한 설문 지를 제외한 205 부가 최종분석에 사용되었다. 자료 분석은 SPSS를 이용하였으며, 요인분석, 신뢰도 검 증(Cronbach's $\alpha)$, 단순회귀분석, 다중회귀분석, $T$-test, 빈도분석 및 기술통계를 실시하였다.

응답자의 인구통계학적 특성을 살펴보면 여성이 $75.1 \%$, 남성이 $24.9 \%$ 였고, 거주지는 서울특별시가 $69.3 \%$, 경기 지역(인천광역시 포함)이 $30.7 \%$ 였다. 연 령은 20 대가 $95.1 \%, 30$ 대가 $4.9 \%$ 였으며, 응답자의 평균 연령은 만 23.9세였다. 직업은 학생이 $80.0 \%$ 로 가장 많았고, 사무직이 $13.2 \%$, 판매/서비스직이 $3.9 \%$, 전문직이 $2.4 \%$, 주부/무직이 $0.5 \%$ 였다. 학력 은 대학교 재학 중이 $69.3 \%$ 로 가장 많았고, 대학교 졸업이 $19.0 \%$, 대학원 재학 중이 $10.2 \%$, 대학원 졸 업이 $0.5 \%$, 고등학교 졸업 이하가 $1.0 \%$ 로 나타났다. 월평균 의복구매비용은 $10 ~ 20$ 만 원 미만이 $34.6 \%$ 로 가장 많았으며, 5 10만 원 미만이 22.9\%, 20 30 만 원 미만이 $16.6 \%, 30 \sim 40$ 만 원 미만이 9.3\%, 5 만 원 미만이 $9.3 \%, 40 \sim 50$ 만 원 이상이 $3.9 \%, 50$ 만 원 이상이 $3.4 \%$ 로 그 뒤를 이었다.

응답자의 페이스북 사용현황을 살펴보면 하루 평 균 페이스북 접속 횟수는 5.1 회였으며, 1 회 평균 페 이스북 접속 시간은 7.4 분이었고, 페이스북 페이지 를 구독한 경험이 있는 패션 브랜드의 개수는 평균 7.8 개인 것으로 나타났다. 패션 브랜드의 페이스북 페이지에 리플을 달거나 “좋아요”를 클릭해 본 경 험에 관해서는 “예”라는 응답이 $75.1 \%$, "아니오"가 $24.9 \%$ 였다. 1 주일 평균 패션 브랜드 페이스북 페이 지 방문횟수는 2.1 회였으며, 1 회 평균 패션 브랜드 페이스북 페이지 방문 시간은 3.3 분인 것으로 나타 났다.

\section{Results and Discussion}

1. Factor analysis of fashion brand SNS characteristics

패션 브랜드 SNS 특성의 요인을 도출하기 위하
여 요인분석을 실시한 결과, 총 3 개의 요인이 추출 되었으며, 구체적인 요인분석 결과는 〈Table 1〉과 같다. 요인 1 은 $\mathrm{SNS}$ 에서 제공되는 이벤트나 콘텐 츠로부터 느끼는 재미와 즐거움, 흥미의 정도와 관 련되어 ‘유희성'이라 명명하였고, 요인 2는 SNS에 서 정보의 공유, 의사소통을 행하면서 유대감을 느 끼고 관계를 맺는 정도를 나타내어 '상호작용성'이 라 명명하였다. 요인 3 은 $\mathrm{SNS}$ 에서 제공되는 정보 의 유용성, 최신성, 전문성, 다양성, 충실성 정도와 관련되어 ‘정보제공성’이라 명명하였다. 총 설명분 산은 $63.078 \%$ 로 나타났다.

한편, 측정문항의 내적 일관성을 확인하기 위하 여 신뢰도 검증(Cronbach's $\alpha)$ 을 실시한 결과, 3 개 의 요인 모두 Cronbach's $\alpha$ 값이 0.8 이상으로 나타 나, 높은 신뢰도를 확보한 것으로 확인되었다.

\section{The effects of fashion brand SNS charac-} teristics on satisfaction

패션 브랜드 SNS의 특성이 만족에 미치는 영향 에 관하여 다중회귀분석을 실시한 결과, 〈Table 2〉 에서 볼 수 있듯이 유희성과 상호작용성, 정보제공 성 모두 만족에 유의한 영향을 미치는 것으로 나타 났다 $(F=119.262, p=.000)$. 따라서 패션 브랜드 SNS 의 특성이 만족에 긍정적 영향을 미칠 것이라는 가 설 1 , 가설 2 , 가설 3 은 모두 채택되었다. 전체 모형 의 설명력은 $63.5 \%$ 였으며, 유희성이 만족에 대해 가장 큰 영향력을 갖고 있었고 $(\beta=.490)$, 정보제공 성 $(\beta=.258)$, 상호작용성 $(\beta=.189)$ 이 그 뒤를 이었 다. 이는 SNS의 유희성이 만족에 유의한 영향을 미 치는 것으로 나타난 $\operatorname{Kim}(2012)$ 의 연구와 상호작용 성이 만족에 유의한 영향을 미치는 것으로 나타난 Lee and Lee(2012)의 연구, 그리고 정보제공성이 만 족에 유의한 영향을 미치는 것으로 나타난 $\mathrm{Kim}$ (2012), Lee(2011)의 연구를 지지하는 결과였다.

\section{Relationship quality according to fashion brand SNS}

1) The effect of satisfaction for fashion brand SNS on trust and commitment

패션 브랜드 SNS에 대한 만족이 신뢰에 미치는 
$\langle$ Table 1〉 Factor analysis for fashion brand SNS characteristics

\begin{tabular}{|c|c|c|c|c|}
\hline Factor & Item & $\begin{array}{l}\text { Factor } \\
\text { loading }\end{array}$ & $\begin{array}{l}\text { Eigen value } \\
\text { (Variance \%) }\end{array}$ & $\begin{array}{c}\text { Reliability } \\
\text { (Cronbach's } \alpha)\end{array}$ \\
\hline \multirow{5}{*}{ Entertainment } & Fashion brand Facebook stimulates my curiosity. & .793 & \multirow{5}{*}{$\begin{array}{c}3.43 \\
(22.917)\end{array}$} & \multirow{5}{*}{.877} \\
\hline & The contents of fashion brand Facebook are interesting. & .827 & & \\
\hline & The various events of fashion brand Facebook give me pleasure. & .725 & & \\
\hline & Using fashion brand Facebook is fun. & .795 & & \\
\hline & $\begin{array}{l}\text { It is possible to see interesting pictures or information about the } \\
\text { fashion brand's product and service by fashion brand Facebook. }\end{array}$ & .686 & & \\
\hline \multirow{5}{*}{ Interactivity } & $\begin{array}{l}\text { It is possible to communicate with the brand by fashion brand } \\
\text { Facebook. }\end{array}$ & .803 & \multirow{5}{*}{$\begin{array}{c}3.051 \\
(43.257)\end{array}$} & \multirow{5}{*}{.815} \\
\hline & $\begin{array}{l}\text { It is possible to form sympathy quickly with other users by } \\
\text { fashion brand Facebook. }\end{array}$ & .696 & & \\
\hline & $\begin{array}{l}\text { It is possible to share a variety of information with others by } \\
\text { fashion brand Facebook. }\end{array}$ & .722 & & \\
\hline & $\begin{array}{l}\text { It is possible to deliver my opinion easily to others by fashion } \\
\text { brand Facebook. }\end{array}$ & 602 & & \\
\hline & $\begin{array}{l}\text { Fashion brand Facebook helps me build the relationship with } \\
\text { the brand. }\end{array}$ & 690 & & \\
\hline \multirow{5}{*}{$\begin{array}{l}\text { Providing } \\
\text { information }\end{array}$} & $\begin{array}{l}\text { Fashion brand Facebook provides useful information about the } \\
\text { brand's product and service. }\end{array}$ & 621 & \multirow{5}{*}{$\begin{array}{c}2.973 \\
(63.078)\end{array}$} & \multirow{5}{*}{.827} \\
\hline & $\begin{array}{l}\text { Fashion brand Facebook provides the latest information about } \\
\text { the brand's product and service. }\end{array}$ & .622 & & \\
\hline & $\begin{array}{l}\text { Fashion brand Facebook provides special information about the } \\
\text { brand's product and service. }\end{array}$ & .822 & & \\
\hline & Fashion brand Facebook provides various kinds of information. & 648 & & \\
\hline & Fashion brand Facebook provides substantial information. & .786 & & \\
\hline
\end{tabular}

$\langle$ Table 2〉 The effects of fashion brand SNS characteristics on satisfaction

\begin{tabular}{|c|c|c|c|c|c|}
\hline \multirow{2}{*}{$\begin{array}{l}\text { Dependent } \\
\text { variable }\end{array}$} & \multirow{2}{*}{$\begin{array}{l}\text { Independent } \\
\text { variable }\end{array}$} & \multicolumn{2}{|c|}{$\begin{array}{l}\text { Unstandardized } \\
\text { coefficients }\end{array}$} & \multirow{2}{*}{$\begin{array}{c}\begin{array}{c}\text { Standardized } \\
\text { coefficient }\end{array} \\
\text { Std. } \beta\end{array}$} & \multirow[t]{2}{*}{$t$} \\
\hline & & $\beta$ & Standard error & & \\
\hline \multirow{4}{*}{ Satisfaction } & Entertainment & .489 & .054 & .490 & $9.120 * * *$ \\
\hline & Interactivity & .216 & .063 & .189 & $3.443 * *$ \\
\hline & Providing information & .276 & .059 & .258 & $4.647^{* * *}$ \\
\hline & \multicolumn{5}{|c|}{$R^{2}=640$, adj $R^{2}=.635, F=119.262 * * *$} \\
\hline
\end{tabular}

${ }^{*} p<.05, * * p<.01, * * * p<.001$

영향에 관하여 회귀분석을 실시한 결과는 〈Table $3\rangle$ 과 같다. 분석 결과, 만족은 신뢰에 유의한 영향 을 미치는 것으로 나타났으며 $(F=191.938, p=.000)$, 모형의 설명력은 $48.3 \%$ 였다. 한편, 패션 브랜드 SNS
에 대한 만족이 몰입에 미치는 영향에 관하여 회귀 분석을 실시한 결과는 〈Table 3 >과 같다. 분석 결 과, 만족은 몰입에 유의한 영향을 미치는 것으로 나타났으며 $(F=154.015, p=.000)$, 모형의 설명력은 
$\langle$ Table 3〉 Relationship quality according to fashion brand SNS

\begin{tabular}{l|l|c|c|c|c|c|c}
\hline \multirow{2}{*}{$\begin{array}{c}\text { Dependent } \\
\text { variable }\end{array}$} & \multirow{2}{*}{$\begin{array}{c}\text { Independent } \\
\text { variable }\end{array}$} & \multicolumn{2}{|c|}{$\begin{array}{c}\text { Unstandardized } \\
\text { coefficients }\end{array}$} & $\begin{array}{c}\text { Standardized } \\
\text { coefficient }\end{array}$ & \multirow{2}{*}{$t$} & $\begin{array}{c}R^{2} \\
\left.\text { (adj } R^{2}\right)\end{array}$ & $F$ \\
\cline { 3 - 7 } & & $\beta$ & Standard error & Std. $\beta$ & & & \\
\hline Trust & Satisfaction & .653 & .047 & .697 & $13.854^{* * *}$ & $.486(.483)$ & $191.938^{* * *}$ \\
\hline Commitment & Satisfaction & .713 & .057 & .657 & $12.410^{* * *}$ & $.431(.429)$ & $154.015^{* * *}$ \\
\hline Commitment & Trust & .686 & .066 & .592 & $10.456^{* * *}$ & $.350(.347)$ & $109.319^{* * *}$ \\
\hline
\end{tabular}

${ }^{*} p<.05, * * p<.01, * * * p<.001$

$42.9 \%$ 였다. 따라서 패션 브랜드 SNS에 대한 만족 이 신뢰와 몰입에 각각 긍정적 영향을 미칠 것이라 는 가설 4 , 가설 5 는 모두 채택되었음을 알 수 있었 다. 이는 SNS에 대한 만족이 신뢰도 및 몰입도 형 성에 유의한 영향을 주는 것으로 나타난 Lee and Lee(2012)의 연구를 지지하는 결과였다.

2) The effect of trust to fashion brand SNS on commitment

패션 브랜드 SNS에 대한 신뢰가 몰입에 미치는 영향에 관하여 회귀분석을 실시한 결과는 〈Table $3>$ 과 같다. 분석 결과, 신뢰는 몰입에 유의한 영향 을 미치는 것으로 나타났으며 $(F=109.319, p=.000)$, 모형의 설명력은 $34.7 \%$ 였다. 따라서 패션 브랜드 $\mathrm{SNS}$ 에 대한 신뢰가 몰입에 긍정적 영향을 미칠 것 이라는 가설 6이 채택되었음을 알 수 있었다. 이는 신뢰가 몰입에 유의한 영향을 주는 것으로 나타난 기존의 선행연구들을 지지하는 결과였다.

4. The effects of trust and commitment on fashion brand SNS on purchase intention

패션 브랜드 SNS에 대한 신뢰와 몰입이 구매의 도에 미치는 영향에 관하여 회귀분석을 실시한 결
과는 〈Table 4〉와 같다. 분석 결과, 신뢰와 몰입은 모두 구매의도에 유의한 영향을 미치는 것으로 확 인되었다 $(F=119.049, p=.000)$. 따라서 패션 브랜드 $\mathrm{SNS}$ 에 대한 신뢰와 몰입이 구매의도에 각각 긍정 적 영향을 미칠 것이라는 가설 7 , 가설 8 이 채택되 었음을 알 수 있었다. 전체 모형의 설명력은 53.6\% 였으며, 몰입( $\beta=.478)$ 이 신뢰( $\beta=.343)$ 보다 구매의 도에 조금 더 유의한 영향을 미치는 것으로 나타났 다. 이는 신뢰와 몰입이 구매의도에 유의한 영향을 주는 것으로 나타난 Garbarino and Johnson(1999), Moorman et al.(1993), Morgan and Hunt(1994), Raj (1982)의 연구를 지지하는 결과였다.

\section{The differences between the fashion involve-} ment groups

패션관여도에 따른 집단 간 SNS 특성의 지각, 관계의 질, 구매의도의 차이를 비교분석하기 위해 패션관여도의 평균값 3.83 을 분리점으로 설정한 후 두 집단으로 나누어 $T$-test를 실시한 결과는 〈Table $5>$ 와 같다. 집단 1 은 패션관여도 값이 3.83 이상인 집단으로, 패션 제품에 대한 관심이 높고 패션의 즐 거움, 유행성, 상징성을 모두 중요하게 생각하여 '패 션고관여 집단’이라 명명하였다. 집단 2는 패션관

$\langle$ Table 4〉 The effect of trust and commitment on fashion brand SNS on purchase intention

\begin{tabular}{c|l|c|c|c|c}
\hline \multirow{2}{*}{$\begin{array}{c}\text { Dependent } \\
\text { variable }\end{array}$} & $\begin{array}{c}\text { Independent } \\
\text { variable }\end{array}$ & \multicolumn{2}{|c|}{$\begin{array}{c}\text { Unstandardized } \\
\text { coefficients }\end{array}$} & $\begin{array}{c}\text { Standardized } \\
\text { coefficient }\end{array}$ & \multirow{2}{*}{$t$} \\
\cline { 2 - 5 } & & $\beta$ & Standard error & Std. $\beta$ & \\
\hline \multirow{3}{*}{\begin{tabular}{c} 
Purchase intention \\
\cline { 2 - 5 }
\end{tabular}} & Trust & .437 & .075 & .343 & $5.804^{* * *}$ \\
\cline { 2 - 5 } & Commitment & .526 & .065 & .478 & $8.093^{* * *}$ \\
\cline { 2 - 5 } & \multicolumn{5}{c}{$R^{2}=.541$, adj $R^{2}=.536, F=119.049^{* * *}$} \\
\hline
\end{tabular}

${ }^{*} p<.05, * * p<.01, * * * p<.001$ 
$\langle$ Table 5〉 The differences in fashion SNS characteristics, relationship quality, and purchase intention between the fashion involvement groups

\begin{tabular}{l|l|c|c|c}
\hline \multicolumn{2}{|c|}{ Group } & $\begin{array}{c}\text { The high fashion } \\
\text { Factor }\end{array}$ & $\begin{array}{c}\text { The low fashion } \\
\text { involvement group(N=114) }\end{array}$ & $t$ \\
\hline \multirow{3}{*}{$\begin{array}{c}\text { Fashion brand } \\
\text { SNS characteristics }\end{array}$} & Entertainment & 4.08 & 3.44 & $6.750^{* * * *}$ \\
\cline { 2 - 5 } & Interactivity & 4.00 & 3.39 & $7.600^{* * * *}$ \\
\cline { 2 - 5 } & Providing information & 4.02 & 3.43 & $6.726^{* * *}$ \\
\hline \multirow{4}{*}{\begin{tabular}{c} 
Relationship quality \\
\cline { 2 - 5 }
\end{tabular}} & Satisfaction & 3.77 & 3.09 & $7.437^{* * *}$ \\
\cline { 2 - 5 } & Trust & 3.58 & 3.05 & $5.854^{* * *}$ \\
\cline { 2 - 5 } & Commitment & 3.24 & 2.57 & $6.511^{* * *}$ \\
\hline
\end{tabular}

$* p<.05, * * p<.01, * * * p<.001$

여도 값이 3.83 미만인 집단으로, 패션 제품에 대한 관심이 낮고 패션의 즐거움과 유행성, 상징성을 별 로 중요하게 생각하지 않아 ‘패션저관여 집단'이라 명명하였다. 각 집단에 속한 응답자의 수를 살펴보 면 패션고관여 집단은 114 명, 패션저관여 집단은 91명이었으며, 두 집단은 SNS 특성, 관계의 질, 구 매의도에서 모두 유의한 차이를 보이는 것으로 나 타났다.

분석 결과, 패션고관여 집단은 패션 브랜드 SNS 의 특성인 유희성, 상호작용성, 정보제공성에 대한 평가가 모두 통계적으로 유의한 수준에서 패션저 관여 집단보다 높게 나타났다. 만족, 신뢰, 몰입으 로 구성되는 관계의 질 또한 패션고관여 집단이 패 션저관여 집단보다 통계적으로 유의한 수준에서 높은 것으로 확인되었고, 구매의도 역시 패션고관 여 집단이 패션저관여 집단보다 통계적으로 유의 한 수준에서 높게 나타났다. 이를 통해 패션관여도 가 높을수록 패션 브랜드 SNS 특성의 지각, 관계의 질, 구매의도가 높을 것이라는 가설 9 가 채택되었 음을 알 수 있었다. 이는 패션관여도에 따라 집단 간에 다양한 측면에서 유의한 차이가 존재하는 것 으로 확인된 기존의 연구들( $\mathrm{Ha} \& \mathrm{Kim}, 2008 ; \mathrm{Kim}$ \& Hwang, 2013; Song \& Hwang, 2007)을 지지하는 결과였다.

\section{Conclusion}

본 연구에서는 페이스북을 중심으로 패션 브랜
드의 SNS 마케팅 활동이 관계의 질 형성에 미치는 영향과 이에 따른 구매의도에 관하여 살펴보았으 며, 조절변수로서 패션관여도에 따른 집단 간 차이 에 대해 알아보았다. 본 연구의 결과는 다음과 같다.

첫째, 패션 브랜드 $\mathrm{SNS}$ 의 특성인 유희성, 상호 작용성, 정보제공성은 $\mathrm{SNS}$ 이용자의 만족에 긍정 적 영향을 미치는 것으로 나타났다. 특히 유희성은 만족에 대해 가장 큰 영향력을 갖는 것으로 확인되 었다. 이는 패션 브랜드들이 SNS를 통해 소비자들 의 호기심을 자극할만한 흥미롭고 재미있는 메시 지를 전달해야 하며, 다양하고 즐거운 이벤트 및 콘텐츠를 지속적으로 제공함으로써 이용자의 만족 도를 제고시켜야 함을 의미한다. 또한, 패션 브랜드 들은 타 매체를 통해서는 쉽게 접하지 못하는, 제 품 및 서비스에 관한 전문적이고 최신의 유용한 정 보들을 자사의 SNS에 꾸준히 업데이트해야 할 것 이며, 이와 더불어 SNS가 소비자-브랜드, 소비자소비자 간의 즉각적이고 상호적인 소통의 장이 될 수 있도록 모색함으로써 SNS 이용자의 만족도를 높여야 할 것이다. 결론적으로 본 연구의 결과는 패션 브랜드가 SNS 마케팅 전략 수립 시 유희성과 정보제공성, 상호작용성을 모두 총체적으로 고려해 야 함을 시사한다.

둘째, 패션 브랜드 SNS에 대한 만족은 신뢰와 몰 입에 긍정적 영향을 미치는 것으로 나타났으며, 패 션 브랜드 SNS에 대한 신뢰는 몰입에 긍정적 영향 을 미치는 것으로 확인되었다. 이는 패션 브랜드들 이 자사 SNS의 성실한 참여자, 즉 높은 몰입도의 
팬(fan)을 형성하기 위해서는 이용자들의 SNS 운영 방식에 대한 만족, $\mathrm{SNS}$ 를 통해 접하는 브랜드 관련 정보 및 홍보에 대한 신뢰가 선행되어야 함을 시사 한다. 따라서 패션 브랜드들은 SNS의 콘텐츠를 다 양화하여 이용자들이 패션 브랜드 SNS 이용에 대 해 만족할 수 있도록 노력해야 할 것이며, 이용자 들이 SNS상에 올리는 제품 및 서비스에 관한 솔직 한 평가를 임의로 조작 또는 삭제하지 말아야 할 것이다.

셋째, 패션 브랜드 SNS에 대한 신뢰와 몰입은 구매의도에 긍정적 영향을 미치는 것으로 확인되 었다. 이는 이용자들이 패션 브랜드 SNS를 통해 접 하는 제품 및 서비스 관련 정보에 대해 크게 신뢰 할수록 구매의도가 높아지며, SNS 활동을 통해 이 용자들의 해당 브랜드에 대한 소속감 및 장기적 관 계 유지, 즉 몰입도가 커질수록 SNS상의 정보를 바 탕으로 한 구매의향이 커짐을 의미한다. 따라서 패 션 기업들은 SNS 마케팅 캠페인 시 소비자의 신뢰 와 몰입을 높여 실제적인 매출 증대로까지 이어질 수 있도록 해야 할 것이다.

넷째, 패션관여도에 따라 패션고관여 집단과 패 션저관여 집단을 나누었으며, 두 집단 간 패션 브랜 드 SNS 특성의 지각, 관계의 질, 구매의도의 차이는 통계적으로 모두 유의한 것으로 확인되었다. 즉, 평 소 패션에 관심이 많고 패션을 통해 기쁨과 즐거움 을 느끼는 소비자일수록 SNS 특성의 지각, 만족, 신 뢰, 몰입, 나아가 구매의도에 보다 높게 반응하는 것 으로 나타났다. 이는 패션 브랜드들이 SNS 마케팅 전략 수립 시 패션관여도가 높은 소비자 집단을 공 략해야 자사의 수익성과 직결됨을 시사한다.

위와 같은 결과를 토대로 본 연구가 제시하는 향 후 연구의 방향은 다음과 같다.

첫째, 본 연구는 패션 기업 측면에서 고효율의 마 케팅적 가치를 지니는 SNS의 특성을 도출하고, 이 를 실증적으로 검증하였다는 점에서 의의를 지닌 다. 불특정 다수를 대상으로 매스 커뮤니케이션을 펼치는 기존의 미디어와 달리, SNS는 자사의 제품 및 서비스에 관심이 있는 소비자들을 중심으로 양 방향 커뮤니케이션을 실시할 수 있기에 비용 대비 고효율의 마케팅 도구라 할 수 있다. 따라서 향후 $\mathrm{SNS}$ 를 활용하여 다양한 마케팅 전략을 수립하고자
하는 패션 기업들은 본 연구에서 규명된 패션 브랜 드 SNS의 주요 특성인 유희성, 상호작용성, 정보제 공성을 기반으로 콘텐츠를 다각화·체계화해야 할 것이다.

둘째, 본 연구는 패션 브랜드 SNS의 특성, 관계 의 질, 구매의도에 관한 실증적 연구를 진행하여 신뢰성과 타당성이 검증된 측정 항목을 제시함으 로써 후속 연구를 위한 이론적 토대를 마련하였다 는 점에서 의의가 있다. 따라서 향후 연구에서는 본 연구의 결과를 토대로 하여 진일보된 SNS 마케 팅 연구 모델을 제시할 수 있을 것으로 기대한다.

본 연구는 연구 내용 및 방법과 관련하여 다음과 같은 몇 가지 한계점을 지닌다.

첫째, 본 연구는 연구 대상자의 거주지와 연령을 서울, 경기 지역의 20 30대로 한정하여 다양한 연 령대의 이용자들을 포함시키지 못하였다. 본 연구 의 결과를 SNS 이용자 전체로 일반화하는 데 무리 가 있으므로 후속 연구에서는 다양한 지역과 연령 대별로 남녀 표본을 추출해야 할 것이다. 둘째, 본 연구는 패션 브랜드들이 활용하는 다양한 SNS 중 에서 페이스북만을 중심으로 연구를 진행하였다. 오늘날 SNS가 제 3 세대 마케팅 도구로 떠오르고 있 는 만큼 페이스북 이외의 다양한 SNS들에 대한 후 속 연구가 필요할 것이며, SNS의 유형에 따라 패션 브랜드-소비자 관계의 질, 구매의도가 어떻게 달라 지는지에 대한 보다 세부적인 연구가 이루어져야 할 것이다. 셋째, 본 연구는 소비자들이 패션 브랜 드의 SNS에 접속하기 위해 사용하는 기기에 대한 분류 없이 전반적인 SNS의 특성만을 도출하였다. 오늘날 스마트폰 등 모바일 기기의 사용자들이 급 증함에 따라 SNS의 특성 요인들은 더욱 다양화되 고 있다. 따라서 후속 연구에서는 모바일 SNS의 특 성을 분석함으로써 패션 브랜드 SNS의 특성을 세 분화, 구체화시킬 필요가 있을 것으로 사료된다.

\section{References}

Ahn, K. H., Hwang, S. J., \& Jung, C. J.(2010). Fashion marketing(3th ed.). Seoul: Soohaksa.

Anderson, C.(1996). Computer as audience: Mediated interactive messages, Forrest, E., Mizerski, R.(eds.), 
Interactive marketing: The future present. Lincoln, IL: NTC Business Books.

Antil, J. H.(1984). Conceptualization and operationalization of involvement. In Advances in Consumer Research, 11, 203-209.

Bagozzi, R. P., \& Utpal, M. D.(2002). Intentional social action in virtual communities. Journal of Interactive Marketing, 16(2), 2-21.

Blattberg, R. C., \& Deighton, J.(1991). Interactive marketing: exploiting the age of addressability. Sloan Management Review, 33.

Crosby, L. A., Kenneth, R. E., \& Cowles, D.(1990). Relationship quality in service selling: an interpersonal influence perspective. Journal of Marketing, 54(July), 68-81.

Davis, F. D., Bagozzi, R. P., \& Warshaw, P. R.(1992). Extrinsic and intrinsic motivation to use computers in the workplace. Journal of Applied Social Psychology, 22, 1111-1132.

Deighton, J.(1996). The future of interactive marketing. Harvard Business Review, 27(6), 151-162.

Doney, P. M., \& Cannon, J. P.(1997). An examination of the nature of trust in buyer-seller relationships. Journal of Marketing, 61(April), 35-51.

Dwyer, R. F., Schurr, P. H., \& Oh, S.(1987). Developing buyer-seller relationship. Journal of Marketing, 51(April), 11-27.

Engel, J. F., \& Blackwell, R. D.(1982). Consumer behavior(4th ed.). New York: Holt, Rinehart, and Winstion.

Engel, J. F., Blackwell, R. D., \& Minard, P. W.(1990). Consumer behavior, word of mouth communication by the innovator. Journal of Marketing, 33(July), 15-19.

Fornell, C.(1992). A national customer satisfaction barometer: the Swedish experience. Journal of Marketing, 56(January), 6-21.

Gabarino, E., \& Johnson, M.(1999). The different roles of satisfaction, trust, and commitment in customer relationship. Journal of Marketing, 63(April), 70-87.

Ganesan, S.(1994). Determinants of long-term orientation in buyer-seller relationship. Journal of Marketing, 58(April), 1-9.

Ha, J. K., \& Kee, J. H.(2008). A study on the TV media star conformity and information source by the types of fashion involvement. Korean Living Science Association, 17(6), 1197-1204.

Hong, D. U.(2012). The impact of SNS characteristics on attitudes, purchase intention, and recommending behavior. Unpublished master's thesis, Yonsei University, Seoul.

Hwang, S. A., \& Hwang, S. J.(2005). The influences of employees' customer orientation and relationship quality(satisfaction, trust, commitment) on revisit intention and word of mouth intention. Journal of the Korea Service Management Society, $6(2), 151-186$.

Ju, S. R., \& Chung, M. S.(2008). The effects of contact intensity and relationship termination cost as mediators of long-term relational retention: focusing on relationship between fashion retail store and customer. Journal of the Korean Society of Clothing and Textiles, 31(7), 1107-1118.

Kang, E. M., \& Park, E. J.(2003). Impact factors on consumer satisfaction in apparel buying behavior. Journal of the Korean Society of clothing and Textiles, 27(1), 29-39.

Kang, K. H.(2012). A research on SNS(Social Network Service) characteristic influence of company brand attitudes perception by collective intelligence: focused on Facebook. Unpublished master's thesis, Hongik University, Seoul.

Kim, B. G.(2012). Factors affecting the characteristics of SNS on user satisfaction and intention. Journal of Information Technology Applications \& Management, 19(4), 213-225.

Kim, C. W.(2011). A study on the SNS characteristics that affect brand attitude factors. Unpublished master's thesis, Chonnam National University, Gwangju.

Kim, D. M.(2011). A study on the formation of brand loyalty through the corporate SNS. Unpublished master's thesis, Korea University, Seoul. 
Kim, J. H., \& Hwang, J. S.(2013). Effects of fashion involvement and internet shopping familiarity on purchase behavior in mobile fashion shopping. Korean Design Forum, 38, 199-214.

Kim, S. H., \& Oh, Y. S.(2004). The brand marketing strategy using the online community. Information \& Communications Policy, 16(2), 20-37.

Kim, T. H.(2011). How the characteristics of microblog influence brand attitudes according to consumer innovativeness: focused on Twitter. Unpublished master's thesis, Hongik University, Seoul.

Kim, Y. C.(2011). A study on factor of acceptance for mobile fashion application. Unpublished doctoral dissertation, Kookmin University, Seoul.

Korea Internet \& Security Agency(KISA).(2009). Survey on the internet usage.

Korea Internet \& Security Agency(KISA).(2012). 2012 Survey on the internet usage.

Lee, J. S., \& Lee, Y. G.(2012). A study on the effects of social network service characteristics on customers' loyalty. Korea Research Academy of Distribution and Management Review, 15(3), 49-65.

Lee, M. J.(2011). Consumer attitude in the SNS(Social Network Service) communication of enterprise: centering around Twitter. Unpublished master's thesis, Hongik University, Seoul.

Lee, S. H., Yu, J. P., \& Park, S. K.(2009). Antecedents of fashion customer relationship management in discount store. Journal of Consumer Studies, 20(1), 17-34.

Lee, Y. N., Lee, Y. Y., Park, H. H., \& Park, S. H. (2007). The study on brand image by relationship quality (satisfaction, trust, commitment) of family restaurants effects on brand loyalty: focusing on customers at their twenties. Journal of Hotel Resort, 6(2), 221-238.

Marketing Executives Networking Group(MENG).(2008). Social media in marketing.

McDonald, G. W.(1981). Structural exchange and marital interaction. Journal of Marriage and the Family, 43(November), 825-839.
Moorman, C., Deshpande, R., \& Zaltman, G.(1993). Factors affecting trust in market research relationships. Journal of Marketing, 57(January), 81-101.

Morgan, R. M., \& Hunt, S. D.(1994). The commitmenttrust, theory of relationship marketing. Journal of Marketing, 58(July), 20-38.

Oh, S. S.(2010). A study on the uses and gratifications of Twitter and Facebook. Unpublished master's thesis, Hanyang University, Seoul.

Oliver, R. L.(1980). A cognitive model of the antecedents and consequences of satisfaction decision. Journal of Marketing Research, 17(November), 460-490.

Oliver, R. L.(1993). A conceptual model of service quality and service satisfaction. in Advance in service marketing and management, Swarts, T. A., Bowen, D. E., Brown, S. W. eds., Greenwich, CT; JAI Press, 5-86.

Oliver, R. L.(1997). Satisfaction: a behavioral perspective on the consume. Boston: Irwin Mcgraw-Hill.

Raj, S. P.(1982). The effects of advertising on high and low loyalty consumer segments. Journal of Consumer Research, 9(1), 77-89.

Ryu, H. S.(2009). The frenzy of Twitter and evolution of social media. KT Economics Management Institute.

Schemwell, D. J., Cronin, J. J., \& Bullard, W. R.(1994). Relational exchange in service: an empirical investigation of ongoing customer service-provider relationships. International of Service Industry Management, 5(3), 57-68.

Seo, E. K., \& Lee, S. J.(2008). A study of effects on long-term relationship orientation of women's experiential fashion marketing: focused on middle, old aged women. The Journal of the Korean Society of Costumes, 58(3), 34-48.

Smith, J. B.(1998). Buyer-seller relationship: Similarity, relationship management and quality. Psychology \& Marketing, 15(1), 3-21.

Smith, R., \& Swinyard, W.(1983). Information response models: an integrated approach. Journal of Marketing, 
46, 81-93.

Song, S. J., \& Hwang, J. S.(2007). The effect of online word-of-mouth on fashion involvement and internet purchase behavior. Journal of the Korean Society of Clothing and Textiles, 31(3), 410-419.

Swan, J. E., Bower, M. R., \& Richardson, L. D.(1999). Customer trust in the salesperson: an integrative review and meta-Analysis of the empirical literature. Journal of Business Research, 44, 93-107.

Wulf, K. D., Schroder, G. O., \& Iacobucci, D.(2001).
Investments in customer relationship: a crosscountry and cross-industry exploration. Journal of Marketing, 65(October), 33-50.

Yang, S. H.(2012). The impact of company's SNS marketing message types for consumer's brand concept according to their psychological type: around the fan pages of Facebook. Unpublished master's thesis, Hongik University, Seoul.

Yang, Y.(2008). Consumer psychology. Seoul: Hakjisa. 